\title{
The development of a European curriculum in Geriatric Emergency Medicine
}

\begin{abstract}
Older people represent a growing proportion of attendees in Emergency Departments across Europe. Traditionally Emergency Departments have not focused on care for older people especially those with frailty. Similarly, geriatric services have not traditionally focused upon the care of older people in Emergency Departments. This work seeks to bring together the two disciplines of Geriatric and Emergency Medicine through a defined and validated curriculum on Geriatric Emergency Medicine.

Domains and items for inclusion in the curriculum were derived through a combination of literature reviewing and a nominal group workshop. The domains and items underwent validation using a Delphi technique involving the European Societies of Geriatric and Emergency Medicine.

In the development stage, 100 individual learning outcomes were identified, reflecting 16 domains; following the stage 2 validation process, 98 items remained. All items were approved by the relevant EU societies.

In the final validation step, the curriculum was formally approved by the UEMS sections for Geriatric Medicine and Emergency Medicine (responsible for curriculae in the respective disciplines).
\end{abstract}




\section{The development of a European curriculum in Geriatric Emergency Medicine}

\section{Background}

The Emergency Department (ED) is a common entry point into urgent care systems for older patients. Older people use emergency services at a much higher rate than would be expected for their population subgroup ${ }^{1}$. With a substantive shift in the demographics of the ED patient population, it is imperative for the next generation of emergency physicians and geriatricians to develop a joint level of expertise in managing the older person in the ED.

However, Emergency Department teams have not historically had specific training nor guidelines for the care of older people especially aspects relating to frailty and geriatric syndromes, for which a broader, more holistic intervention is considered to be best practice ${ }^{2-5}$. Hence, management of older patients with the primary problem being frailty has been regarded highly complex and time-consuming, as the ED environment has been organised according to single organ assessments and management.

Similarly, geriatric medicine has not traditionally focused on older people in the emergency care context. However, the competencies associated with geriatric medicine, such as delirium identification and management, falls management etc, are as important in the acute care context as they are in the more typical geriatric ward setting.

Emergency Medicine (EM) is a medical specialty based on the knowledge and skills required for the prevention, diagnosis and management of the acute and urgent aspects of illness and injury affecting patients of all age groups with a full spectrum of undifferentiated physical and behavioural disorders (EUSEM definition). The EM specialty includes pre-hospital and emergency department settings. Time is critical because delays in urgent care correlate with adverse outcomes including mortality and morbidity. EM is one of the medical specialties where a collaborative approach improves health outcomes during the first hours following admission to hospital. Currently, only 17 of the 28 member states are recognised by UEMS as having a primary specialty of EM (5-year training program).

Geriatric Medicine (GM) is a specialty of medicine concerned with the physical, mental, functional and social conditions occurring in the acute care, chronic disease, rehabilitation, prevention, social and end of life situations in older patients. This group of patients is considered to have a high degree of frailty and active multiple pathologies, requiring a holistic approach. Diseases may present differently in old age, are often difficult to diagnose, the response to treatment is often delayed and there is frequently a need for social support. Geriatric Medicine therefore exceeds organ-orientated medicine offering additional therapy in a multidisciplinary team setting, the main aim of which is to optimise the functional status of the older person and improve the quality of life and autonomy. Geriatric Medicine is not specifically age-defined but will deal with the typical morbidity found in older patients. Most patients will be over 65 years of age but the problems best dealt with by the specialty of Geriatric Medicine become much more common in the $80+$ age group. It is recognised that for historic and structural reasons the organisation of geriatric medicine may vary between European Member Countries (UEMS definition). 


\section{The development of a European curriculum in Geriatric Emergency Medicine}

Both geriatric medicine and emergency medicine have existing curriculae, aspects of which relate to the general care of older people.

\section{Geriatric Emergency Medicine}

Despite a growing awareness of the importance of geriatric competencies in Europe, there is no specific European Geriatric Emergency Medicine (GEM) curriculum ${ }^{6}$. The purpose of the GEM curriculum is to highlight the competencies that might be expected of emergency department AND geriatric services focusing on the care of predominantly frail older people in the emergency medicine setting. It is the intention that the curriculum will also be useful to all key team members, such as nurses and therapists.

In an attempt to align the two paradigms of Emergency Medicine and Geriatric Medicine, the respective European Societies (EUSEM and EUGMS) created a joint Geriatric Emergency Medicine Special Interest Group (GEMSIG) in 2013. A specific activity of this group was to create the European Taskforce on Geriatric Emergency Medicine (ETFGEM), to develop the GEM curriculum.

\section{Funding}

Funding was provided by both societies to cover travel costs and accommodation for the ETFGEM meeting.

\section{Methods}

As there is no existing European GEM curriculum, a consensus process was used to develop the curriculum. In the first instance a modified Nominal Group Technique (NGT) was used to generate domains and items based on the published literature, which were then broadened and validated using a modified Delphi process.

Review of the literature

Potentially relevant papers were identified from MEDLINE 1996+ using the following search terms: older patients OR geriatric AND emergency medicine. The search was supplemented from the grey literature, personal collections and by hand-searching the references of selected papers. Papers were selected on the basis of their relevance to developing competencies in GEM by agreement between a geriatrician and an emergency physician. A range of articles including North American initiatives to develop a GEM curriculum and recent reviews and key articles in the field were identified and used to inform the development of the domains and items ${ }^{7-17}$. The development focused upon the additional competencies over and above that which would be expected from training in either geriatric medicine or emergency medicine - so this was not simply a reproduction of how to practice emergency medicine in older people, but an attempt to develop higher level competencies that will add value to existing curriculae? ${ }^{7}$. 


\title{
The development of a European curriculum in Geriatric Emergency Medicine
}

\author{
Curriculum development - nominal group method
}

The membership of the joint Geriatric Emergency Medicine Special Interest Group was derived from e-mail and web invitations to members of the European societies of Emergency and Geriatric Medicine, as well as through awareness raising at respective European conferences. Volunteers to participate in the 'Taskforce' to work on the curriculum were invited from the 140 or so members of the Special Interest Group. Eleven volunteers eventually formed the Taskforce (six EUGMS, four EUSEM and one GEM nurse), and participated in a curriculum development weekend in London, United Kingdom in December 2014.

Based on the literature review findings, the panel generated a list of domains and a range of items for potential inclusion in the GEM curriculum. These were discussed openly and modified following the principle of consensus. Following the meeting the draft competencies were e-mailed to the broader Taskforce for initial validation.

\section{Second stage curriculum validation - Delphi process}

The domains and individual items were entered into a spreadsheet and sent out to the boards and Councils of both EUSEM and EUGMS. Participants were asked to respond to each of the domains and items of the pre-Delphi curriculum by stating whether they fully agreed with the learning outcome or not (two choices only). If they did not agree, they were asked to specify why not and what changes they would suggest, if any, that would make the learning outcome acceptable to them. Additionally, responders were asked to give general comments for improvement of the suggested curriculum. An important instruction posed was: Please take into account that the curriculum contains a list of minimal requirements a geriatrician/emergency physician should be able to demonstrate at the end of their specialty training in emergency medicine/geriatric medicine respectively:

Responses were counted, tabulated and copied in full length to the members of the Nominal Group for evaluation. Where there was any ambiguity, the individual Delphi respondent was contacted for clarification. Based on this information, the leads of the Nominal Group revised the curriculum, according to the following principles:

- requests for improving the clarity or wording were checked

- requests for adding a new aspect, or for increasing the difficulty level of an existing objective were only taken into account, if this was most likely an unintentional omission, and would most likely be accepted by all experts from all countries

- requests for deleting an aspect, or for lowering the difficulty level of an existing objective, were evaluated, and if required, personally discussed (by phone or individual email) with the panel member, with the intention of better understanding the request and finding consensus on an acceptable modification. 


\section{The development of a European curriculum in Geriatric Emergency Medicine}

- The Nominal Group leads ensured that any modification did not result in the omission of an objective that was considered relevant by the majority of the Delphi panel or the Nominal Group

Final stage validation

The final stage in the process was to formally submit the curriculum to the Union of European Medical Specialists (UEMS), which regulates European curricula. The proposed curriculum was sent to the UEMS sections on geriatric medicine and emergency medicine for final approvals.

\section{Results}

Following the literature review and initial nominal group meeting involving members of ETGEM, 96 individual learning outcomes were identified, and categorised in the following domains:

- Pre-hospital care

- Assessment

- Triage

- Primary clinical assessment and stabilisation of life threatening conditions

- Secondary clinical assessment

- Clinical assessment in older people - what's different?

- Management of older people - what's different?

- Nonspecific presentations

- Management of geriatric syndromes (e.g. falls, confusion, continence)

- Pitfalls in the management of common conditions - 'atypical presentations'

- Comprehensive Geriatric Assessment (CGA)

- Risk benefit analysis

- Medication: review and reconciliation

- Pain management

- Transitions of care and disposition

- Principles of rehabilitation in older people

- Ethical issues, including advance directives

- Palliative Care

The initial curriculum items were then shared with the broader ETGEM group, leading to no items being removed, but the addition of four items and several points of clarification. 


\section{The development of a European curriculum in Geriatric Emergency Medicine}

The second stage validation in which the draft curriculum was shared with the executive and/or council members of EUSEM and EUGMS obtained responses from 14 EUGMS members and 12 EUSEM members, from 16 EU countries (EUSEM). For the 103 items, the overall agreement was $2454 / 2509$ (98\%) votes. All but seven items were accepted by $90 \%$ of raters and retained. Of the seven with less than $90 \%$ agreement, one was mainly rejected by EUSEM members ('to be aware of physiological changes that affect ventilation, including reduced compliance and vital capacity') and was removed given that EUSEM members have primary responsibility for ventilation as opposed to EUGMS members.

The second item with $81 \%$ support was 'To be able to organise support for people with dementia and their carers, including post-diagnostic support and advice, personalised services, peer support, housing support, housing-related services and telecare' but the comments indicated that this was felt to be more the role of the broader MultiDisciplinary Team (MDT), rather than being specific to ED staff. Therefore this was modified to reflect the need 'to be aware of the need for, and be able to access' such services, as it was felt that it was an important issue highly relevant to the care of older people in the ED.

The third item with less than $90 \%$ support was addressed similarly to the above ('Explain all newly prescribed drugs to older people and caregivers at discharge, checking that they understand how and why the drug should be taken, the possible side effects, and how and when the drug should be stopped') and was changed to 'To understand the need and be able to access support to help explain newly prescribed drugs to older people and caregivers at discharge, checking that they understand how and why the drug should be taken, the possible side effects, and how and when the drug should be stopped'.

An item on falls ('To be able to employ a framework for assessing falls in older people') received only $88 \%$ support, but the comments (from EUSEM members) indicated that objections were more about not having to undertake a full falls assessment. The item was adjusted as follows 'to be able to use a framework for the initial assessment of falls in older people'.

The item of being able to define the process of CGA was supported by $85 \%$ of respondents, with EUSEM members feeling that this was not their responsibility. Given the importance of holistic assessment of frail older people, this item was modified as follows: 'To be able to describe the domains of Comprehensive Geriatric Assessment (CGA) - namely medical, psychological/cognitive, functional, social and environmental issues'. Similarly the item on knowing how to access CGA pathways was viewed as not 


\section{The development of a European curriculum in Geriatric Emergency Medicine}

being an ED role ( $88 \%$ support), so was clarified as follows 'To be aware of locally agreed pathways to access CGA both in-hospital and in the community setting'.

The item with the lowest rating ( $81 \%)$ which was questioned by both EUGMS and EUSEM members was 'To be able to describe a rehabilitation framework (e.g. International Classification of Function and Heath) that emphasises the importance of rehabilitation following an emergency care episode'). This was rejected, as the practical application of this knowledge (e.g. knowing when and how to access a rehabilitation service) was more important, and was already addressed in other parts of the curriculum.

Other comments were reviewed and incorporated - these were mainly points of clarity or commentary, leaving 98 individual learning outcomes that remained out of the 100 at the start of the second stage process (Figure 1).

In the final validation step, the curriculum was formally submitted to the UEMS sections for Geriatric Medicine and Emergency Medicine (responsible for curriculae in the respective disciplines); both sections approved the curriculum. The final approved version is shown in full in Appendix 1. 


\section{The development of a European curriculum in Geriatric Emergency Medicine}

Figure 1 Developing a European curriculum in Geriatric Emergency Medicine

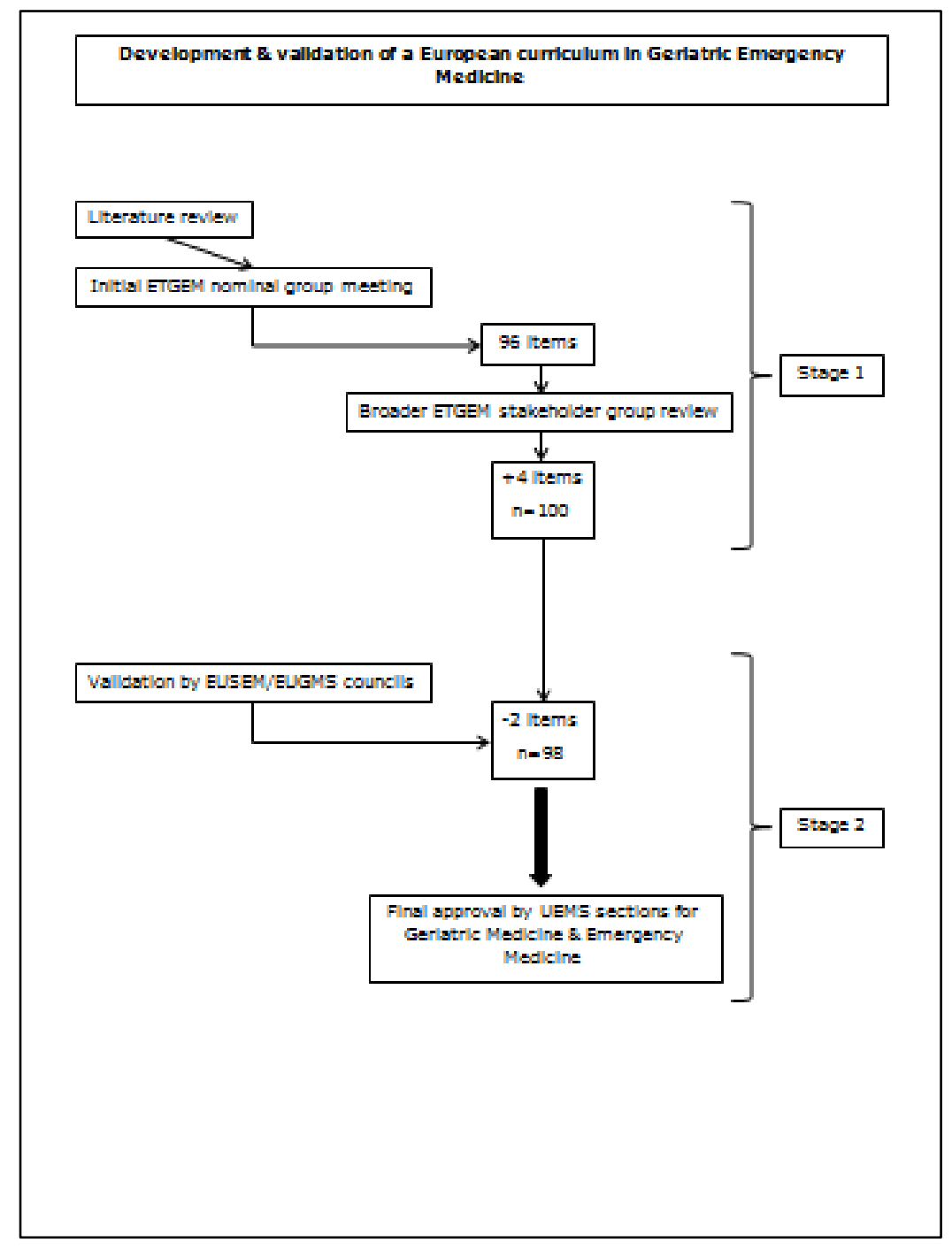

\section{Discussion}

We describe here the development and validation of a European curriculum in Geriatric Emergency Medicine (GEM). Sixteen EU countries were actively involved in the formation and refinement of the curriculum objectives, but the UEMS councils that signed off the final competencies represent $30 \mathrm{EU}$ countries and three affiliated members. The intention is that the curriculum will be disseminated and adopted by the individual national member societies of Emergency and Geriatric Medicine throughout Europe, and it would enhance the care of older people with urgent care needs throughout Europe.

The modified Delphi process did highlight some issues, most of which centered on misinterpretation of what practitioners were being asked to do, most commonly concerns that the totality of care for older people with geriatric syndromes should be undertaken in the ED; these concerns appear to have been addressed by emphasising that the intention is to assess for geriatric syndromes in the ED and be able to undertake initial, 


\section{The development of a European curriculum in Geriatric Emergency Medicine}

urgent management and then signpost patients and carers to sources of on-going support.

Strengths of this curriculum include the robust methodology and consensus building approach, which should in turn facilitate its application in practice, as it is critical to engage stakeholders early to optimise the chances of delivery ${ }^{18}$. A weakness is the lack of patient and public involvement in the process of curriculum development, as frailty and nonspecific presentations are associated with the inability of current clinical management systems to balance goals of care (patient outcomes) against standards of care (evidence based standards). Non-medical organisations were not fully engaged in the development process, but much of the content will be relevant to nurses, therapists and other non-medical professionals working in the ED. However, this validation process focused on medical curriculae. Future iterations of the curriculum could be improved by focusing on "what matters to the patient" rather than "what is the matter with the patient", and by engaging non-medical professionals.

Older people accessing urgent care often present non-specifically with some or all of cognitive impairment, multiple co-morbidities, polypharmacy and concomitant functional impairment. It is hoped that this curriculum will prepare clinicians for better caring for such patient in Emergency Department settings across Europe. Whilst primarily aimed at post-graduate clinicians, many aspects of the curriculum might also be incorporated into undergraduate curriculae, and should be complementary to existing pan-European curriculae through our focus on added value ${ }^{19}$.

The remaining challenge for this initiative is to ensure that the curriculum does become embedded into practice; this will be attempted through widespread dissemination using the GEM collaboration between the EUGMS and EUSEM, by this joint publication in the 'home journals', presentations at conferences, the preparation and provision of tools to enhance learning (textbook and teaching course in development) and future evaluations of uptake. Importantly, the engagement of the UEMS in this curriculum development process should facilitate implementation. There is a parallel process underway to develop a research framework in the field of GEM in Europe. 


\section{The development of a European curriculum in Geriatric Emergency Medicine}

\begin{tabular}{|c|c|c|}
\hline \multicolumn{3}{|c|}{ 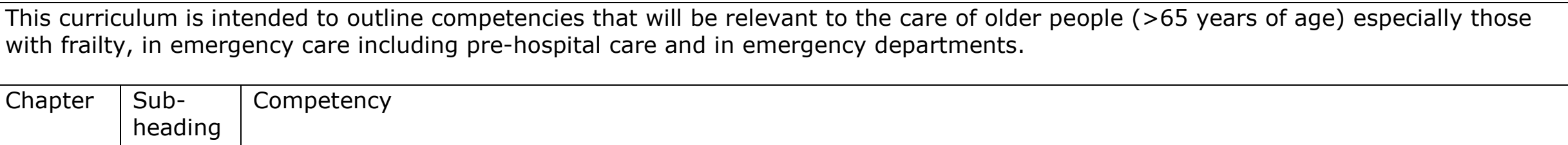 } \\
\hline \multicolumn{3}{|c|}{ Pre-hospital care } \\
\hline & 1 & $\begin{array}{l}\text { To understand the risk of under-triage in older people (i.e. vital signs may be in the normal range, but not normal for } \\
\text { that patients - e.g. normotension in someone with systolic hypertension) }\end{array}$ \\
\hline & 2 & To recognise the need to take a collateral history or documentation about the patients usual status and medical history \\
\hline & 3 & To understand the importance of obtaining an accurate medication history including an assessment of compliance \\
\hline & 4 & $\begin{array}{l}\text { To recognise the importance of capturing the home environment including formal and informal caregivers as part of the } \\
\text { pre-hospital assessment }\end{array}$ \\
\hline & 5 & To be aware of the potential existence of resuscitation order or advance directive that may be in the person home \\
\hline & 6 & $\begin{array}{l}\text { To understand the importance of sensory impairments in older people and the need to ensure patients are conveyed } \\
\text { with their sensory appliances }\end{array}$ \\
\hline & 7 & To be able to recognise high risk presentation in older people which may not be identified using traditional triage scores \\
\hline & 8 & To be aware that conventional physiological parameters may be inadequate to identify older people with severe illness \\
\hline & 9 & To be aware that abnormal physiological parameters may be long-standing in older people \\
\hline & 10 & $\begin{array}{l}\text { Injury mechanisms cannot be used to reliably triage as older people are susceptible to significant trauma from low } \\
\text { energy mechanisms }\end{array}$ \\
\hline & 11 & To ensure that every patient has careful assessment, not based on age \\
\hline & 12 & To be aware that geriatric syndromes such as falls and confusion can be associated with serious underlying problems \\
\hline
\end{tabular}




\section{The development of a European curriculum in Geriatric Emergency Medicine}

\begin{tabular}{|c|c|c|}
\hline & & and act as markers of future prognosis \\
\hline \multicolumn{3}{|c|}{ Primary clinical assessment and stabilisation of life threatening conditions } \\
\hline & 13 & $\begin{array}{l}\text { To know the effects of altered anatomy on airway management (dentition, microstomia, macroglossia, cervical } \\
\text { spondylosis and associated reduced neck extension) }\end{array}$ \\
\hline & 14 & $\begin{array}{l}\text { To be able to adjust rapid sedation medication according to age associated changes in pharmacodynamics \& } \\
\text { pharmacokinetics }\end{array}$ \\
\hline & 16 & $\begin{array}{l}\text { To be aware of the risk of masked cerebral injury (e.g. normal Glasgow Coma Score in people with falls on anti- } \\
\text { coagulation) related to cerebral atrophy and cognitive impairment }\end{array}$ \\
\hline & 17 & $\begin{array}{l}\text { To institute appropriate early monitoring and testing with the understanding that older people may present with muted } \\
\text { signs and symptoms (e.g. absent pain and neurologic changes) and are at risk of occult shock. }\end{array}$ \\
\hline & 18 & $\begin{array}{l}\text { To appreciate the importance of hypothermia as a presenting feature that is associated with high morbidity and } \\
\text { mortality }\end{array}$ \\
\hline \multicolumn{3}{|c|}{ Secondary clinical assessment } \\
\hline & 19 & $\begin{array}{l}\text { To be aware of altered anatomy (e.g. arthritis), physiology, changes related to prosthetic devices (e.g. pacemakers) and } \\
\text { the effects of medication when interpreting the secondary survey }\end{array}$ \\
\hline & 20 & To know common patterns of injury in older people for example, ground level falls with serious sequelae \\
\hline \multicolumn{3}{|c|}{ Clinical assessment in older people - what's different? } \\
\hline & & Communication and history taking \\
\hline & 21 & $\begin{array}{l}\text { The practitioner will be able to recognise the presence of sensory impairment (hearing, sight, speech) or cognitive } \\
\text { impairment that impairs communication }\end{array}$ \\
\hline
\end{tabular}




\section{The development of a European curriculum in Geriatric Emergency Medicine}

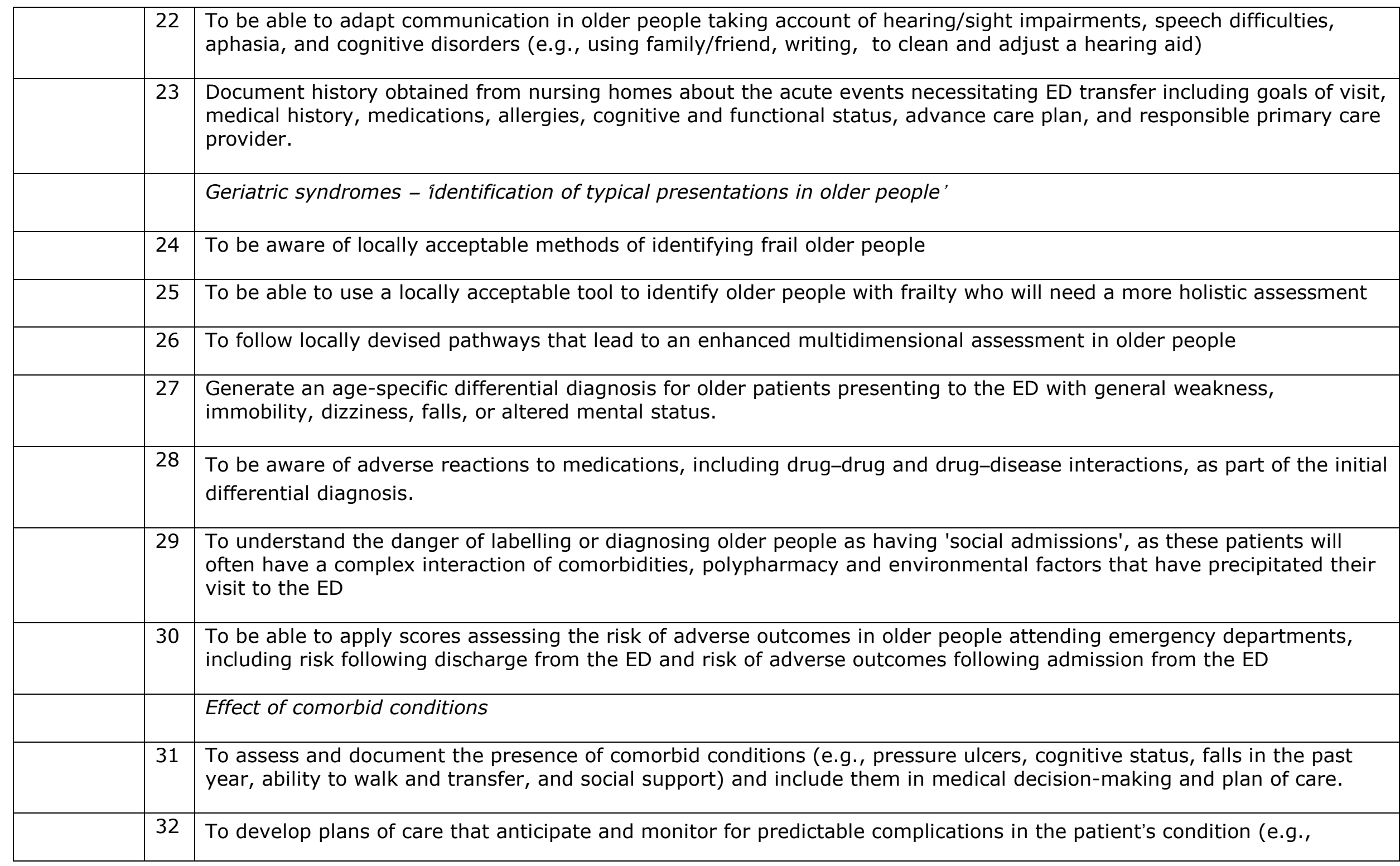




\section{The development of a European curriculum in Geriatric Emergency Medicine}

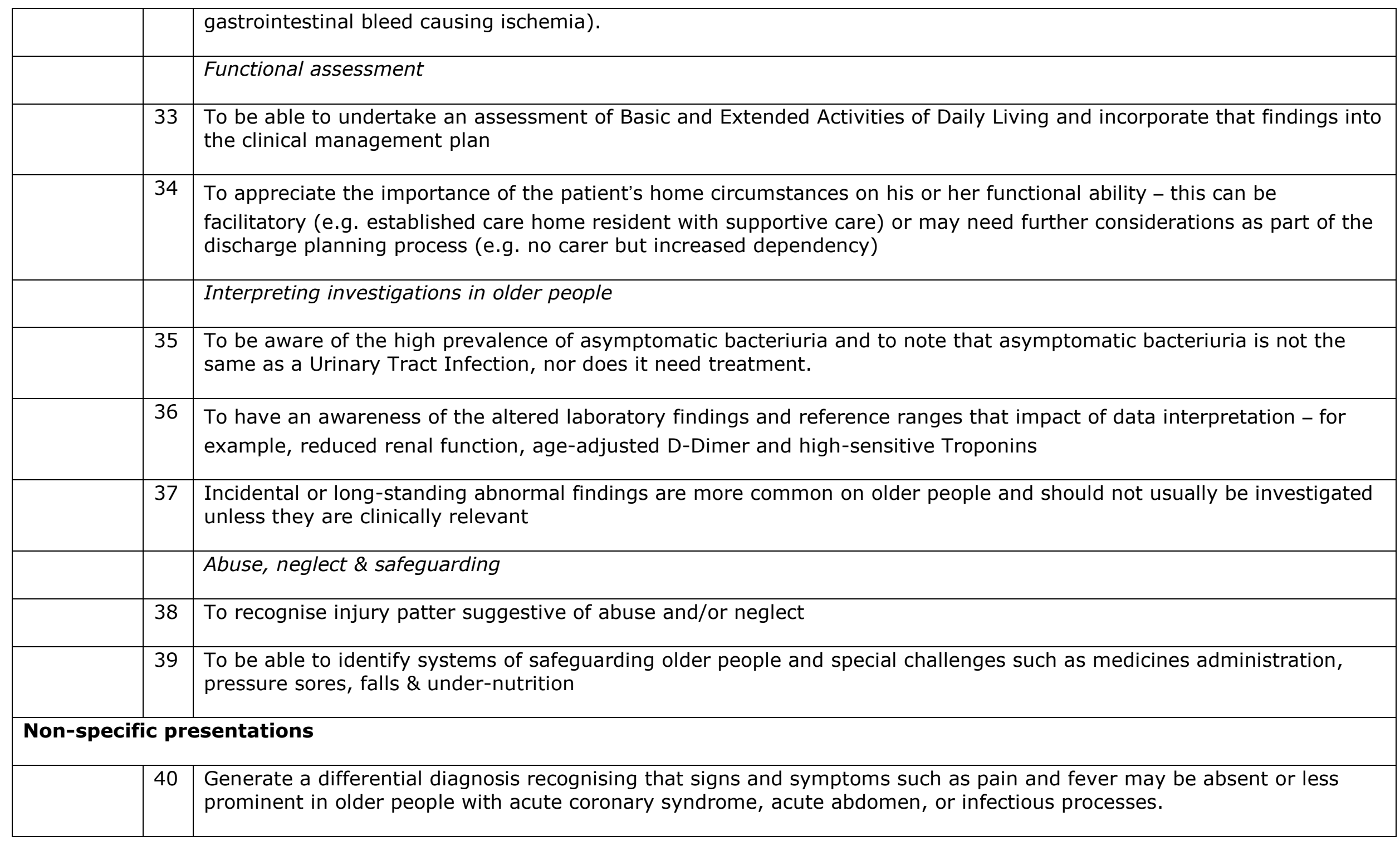




\section{The development of a European curriculum in Geriatric Emergency Medicine}

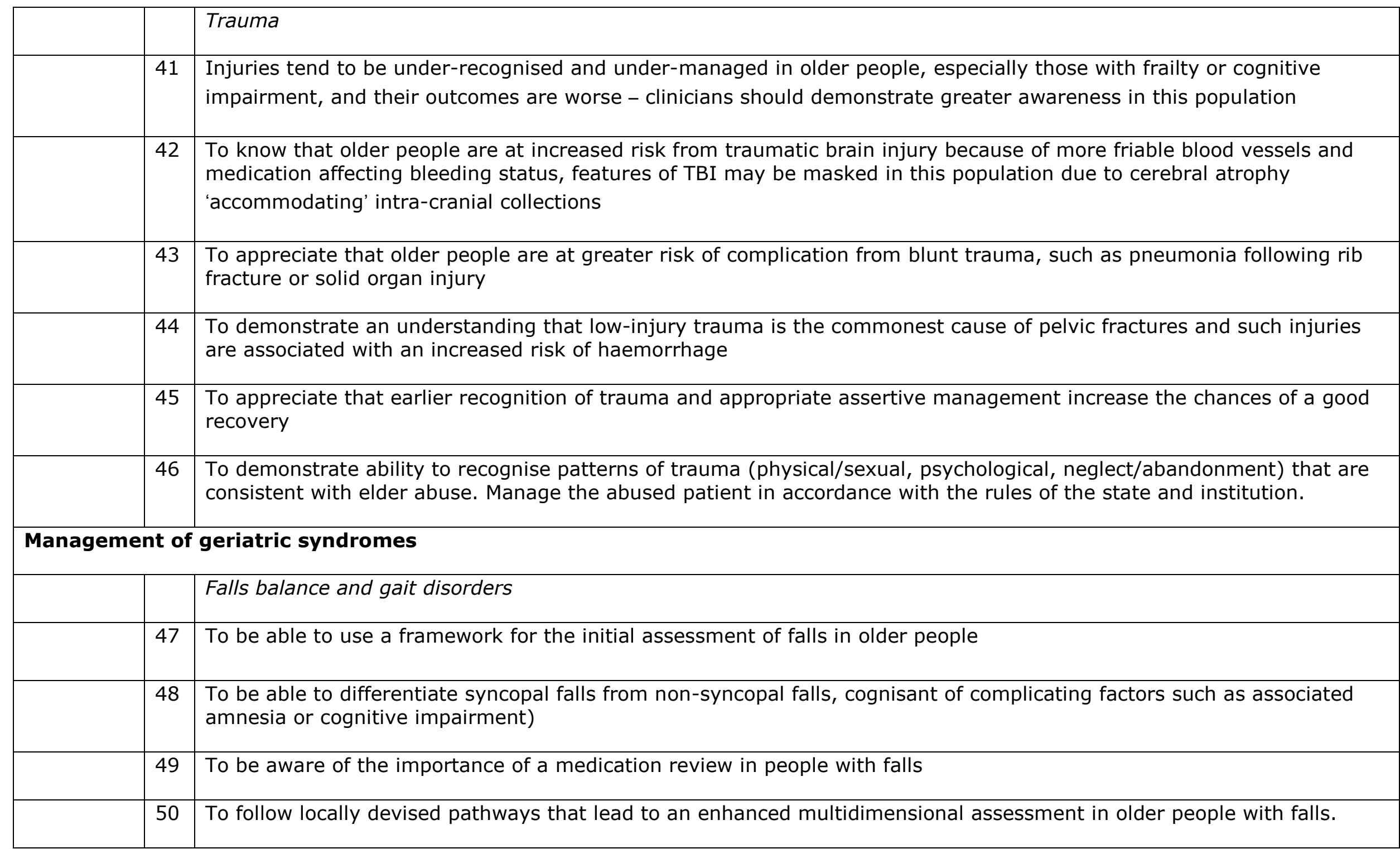




\section{The development of a European curriculum in Geriatric Emergency Medicine}

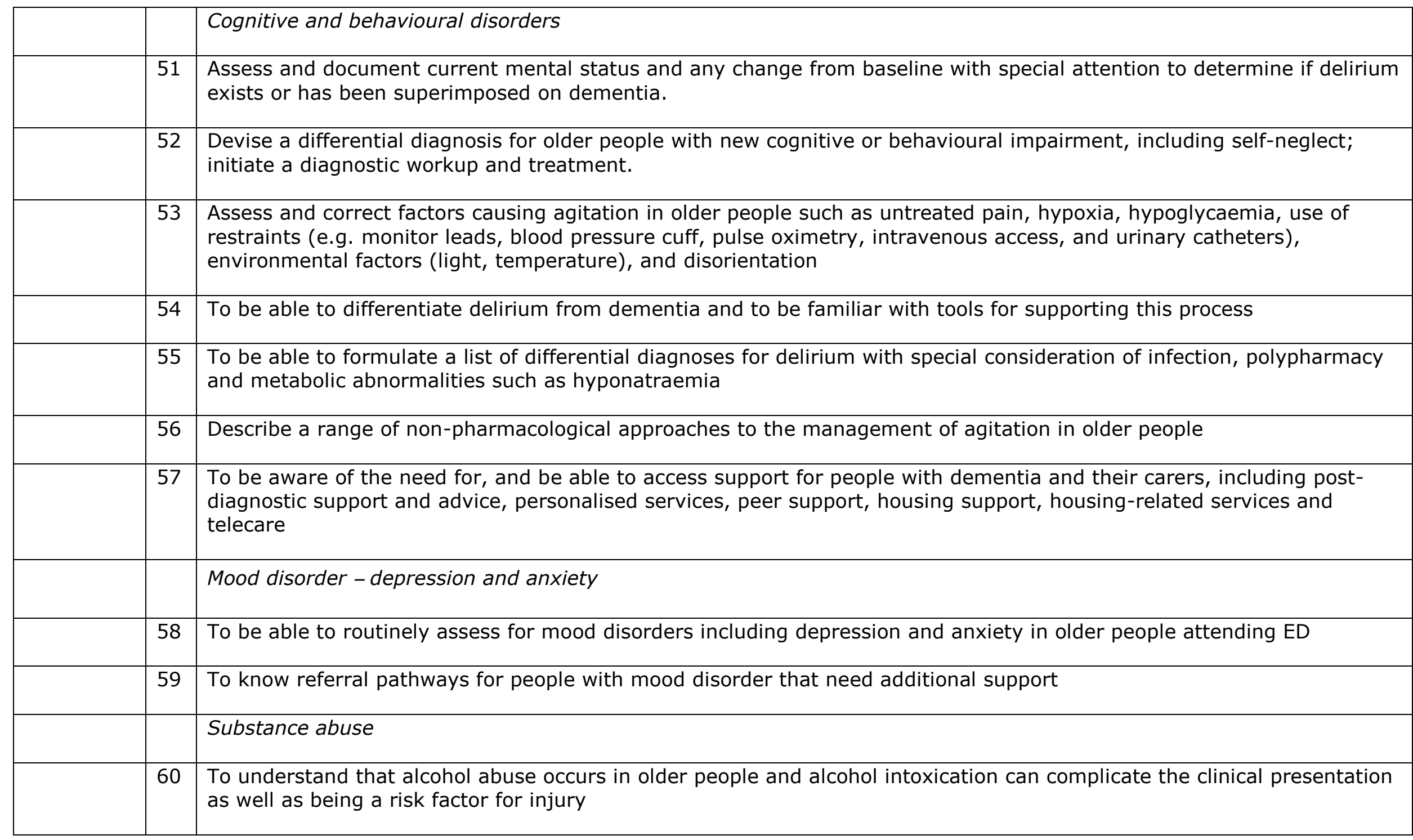




\section{The development of a European curriculum in Geriatric Emergency Medicine}

\begin{tabular}{|c|c|}
\hline & Skin care/pressure sores \\
\hline 61 & $\begin{array}{l}\text { Appreciate that skin damage can occur within } 40 \text { minutes or quicker in older people on hard trolleys/spinal boards, with } \\
\text { additional pre-disposing factors such as diabetes }\end{array}$ \\
\hline 62 & Pressure sores can be a source of occult sepsis \\
\hline \multicolumn{2}{|c|}{ Pitfalls in the management of common conditions - 'atypical presentations' } \\
\hline & $\begin{array}{l}\text { Be aware of the potential dangers in common presentations in older people - some selected examples of how different } \\
\text { things can be are described below: }\end{array}$ \\
\hline 63 & Abdominal pain - think aortic aneurysm, heart attack, constipation \\
\hline 64 & Diarrhoea - think mesenteric ischaemia, sepsis or constipation with overflow more than gastroenteritis \\
\hline 65 & Vomiting - avoid anti-dopaminergic drugs in people with Parkinson's disease \\
\hline 66 & Back pain - think aortic aneurysm, insufficiency fractures or cord compression \\
\hline 67 & Non-specific weakness may not be benign and needs careful evaluation \\
\hline 68 & Chest pain - likely to be cardiac even if non-cardiac sounding \\
\hline \multicolumn{2}{|c|}{ Comprehensive Geriatric Assessment } \\
\hline 69 & $\begin{array}{l}\text { To be able to describe the domains of Comprehensive Geriatric Assessment (CGA) - namely medical, } \\
\text { psychological/cognitive, functional, social and environmental issues }\end{array}$ \\
\hline 70 & To be aware of locally agreed pathways to access CGA both in-hospital and in the community setting \\
\hline
\end{tabular}




\section{The development of a European curriculum in Geriatric Emergency Medicine}

\begin{tabular}{|c|c|}
\hline \multicolumn{2}{|c|}{ Risk benefit analysis } \\
\hline & $\begin{array}{l}\text { To be able to carefully consider the competing risks associated with standard, protocol driven treatment in older people, } \\
\text { for example: }\end{array}$ \\
\hline 71 & $\begin{array}{l}\text { To be able to weigh up the risk of bleeding associated with 'triple therapy' (Aspirin, Clopidogrel and Low Molecular } \\
\text { Weight Heparin) }\end{array}$ \\
\hline 72 & $\begin{array}{l}\text { To appreciate the risk of routine urinary catheters to assess fluid status, that may increase the risk of catheter } \\
\text { associated UTI and sepsis }\end{array}$ \\
\hline 73 & $\begin{array}{l}\text { To appreciate that urinary catheters can cause substantial problems with detrusor instability and urinary } \\
\text { incontinence as well as impairing dignity and increasing the risk of falls }\end{array}$ \\
\hline 74 & $\begin{array}{l}\text { Identify and implement measures that protect older people from developing iatrogenic complications common to } \\
\text { the ED including invasive bladder catheterisation, spinal immobilization, and central line placement. }\end{array}$ \\
\hline \multicolumn{2}{|c|}{ Medication: review and reconciliation } \\
\hline 75 & $\begin{array}{l}\text { To be aware that medication can be a common cause of presentations e.g. bleeding with anti-coagulants, } \\
\text { hypoglycaemia with anti-diabetic medication or toxicity associated with drugs with narrow therapeutic windows }\end{array}$ \\
\hline 76 & $\begin{array}{l}\text { To be aware of the importance that medication reconciliation adds to the clinical assessment and management of older } \\
\text { people }\end{array}$ \\
\hline 76 & Describe the changes in pharmacokinetics and pharmacodynamics seen in older people \\
\hline 78 & $\begin{array}{l}\text { Prescribe appropriate drugs and dosages considering the current medication, acute and chronic diagnoses, functional } \\
\text { status, and knowledge of age-related physiological changes (renal function, central nervous system sensitivity) }\end{array}$ \\
\hline 79 & $\begin{array}{l}\text { Compliance - awareness that older people may not be taking medication as prescribed because of a range of reasons } \\
\text { including side-effects }\end{array}$ \\
\hline
\end{tabular}




\section{The development of a European curriculum in Geriatric Emergency Medicine}

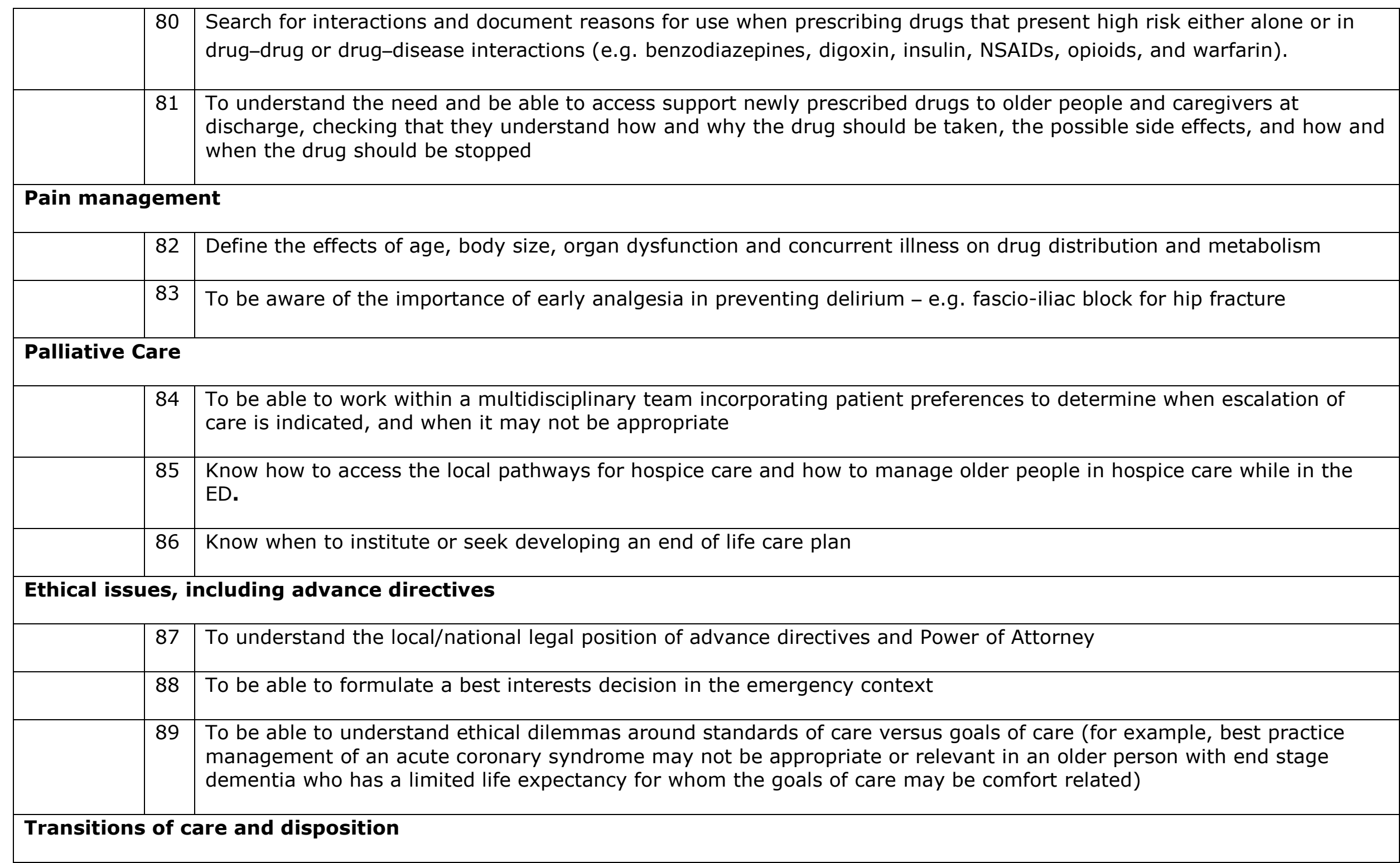




\section{The development of a European curriculum in Geriatric Emergency Medicine}

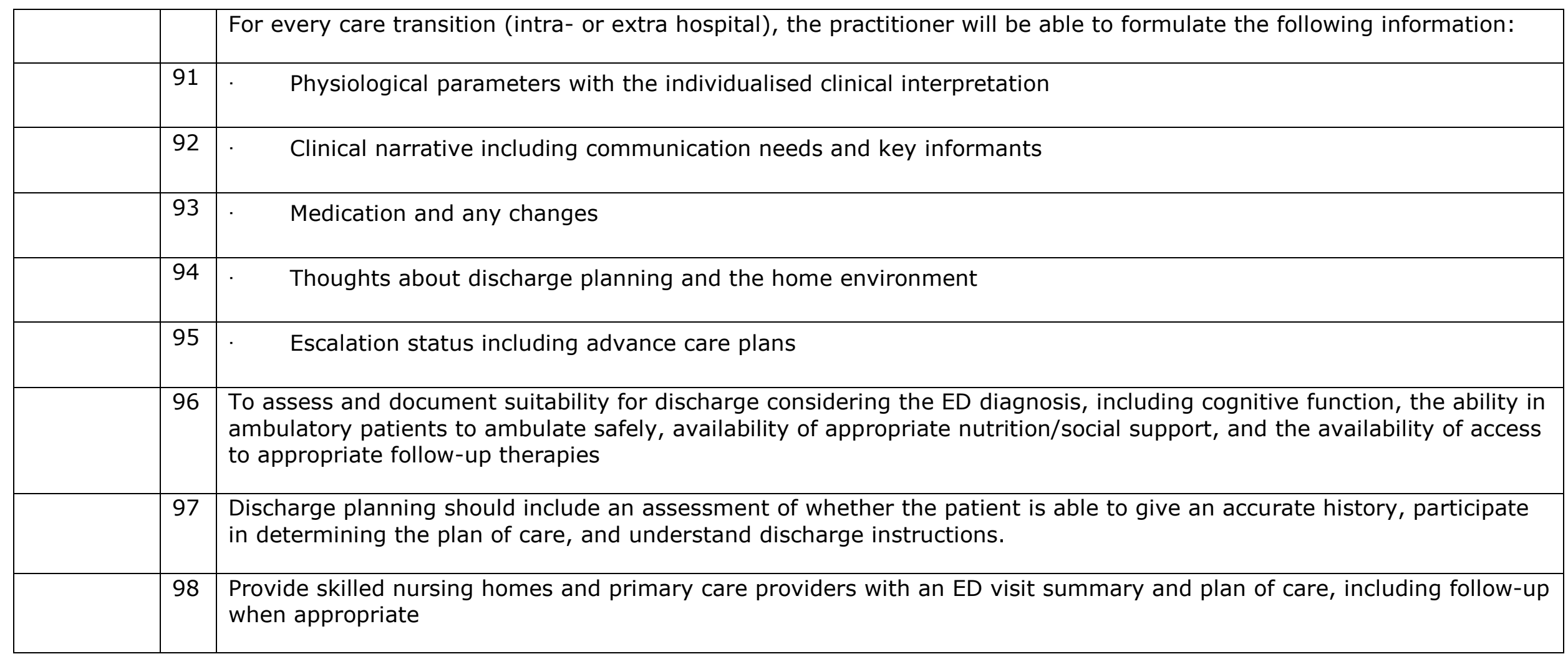




\section{The development of a European curriculum in Geriatric Emergency Medicine}

\section{Acknowledgements}

This work was produced by the European Taskforce on Geriatric Emergency Medicine (ETGEM) of the European Society for Emergency Medicine (EuSEM) and the European Union of Geriatric Medicine Society (EUGMS).

ETGEM was co-chaired by Abdelouahab Bellou, Professor of Emergency Medicine, MD, $\mathrm{PhD}$, Chair of the Section of Geriatric Emergency Medicine of EuSEM and Simon Conroy, MB ChB, PhD, Chair of the Geriatric Emergency Medicine Interest Group of EUGMS.

Members of the ETGEM included:

EuSEM: Jay Banerjee (UK), Abdelouahab Bellou (FR/USA, Chair), Olivier Ganansia (FR), Alexandre Jeleef (FR), Christian H. Nickel (SW), Marc Sabbe (BE), Richard Wolfe (USA).

EUGMS: Anna Björg Jónsdóttir (IS), Simon Conroy (UK, Chair), Els Devriendt (BE), Maria Fernandez (ES), F. Javier Martín-Sánchez (ES), Simon Mooijaart, (NL), Fredrik Sjöstrand (SE), Regina Roller-Wirnsberger (AU).

The authors are grateful to all of the contributors of ETGEM, the UEMS GM and EM sections, and well as the broader membership of EUGMS and EUSEM for their input to this document.

Specific thanks are offered to Barbara Hogan (EUSEM president), Timo Strandberg (EUGMS president) and David Williams \& Tahir Masud (UEMS education leads). 


\section{The development of a European curriculum in Geriatric Emergency Medicine}

\section{References}

1. Blunt I, Bardsley M, Dixon J. Trends in emergency admissions in England 2004 2009: is greater efficiency breeding inefficiency? London: Nuffield Trust;2010.

2. Ellis G, Whitehead M, O'Neill D, Robinson D, Langhorne P. Comprehensive geriatric assessment for older adults admitted to hospital. . Cochrane Library. 2011.

3. Baztan JJ, Suarez-Garcia FM, Lopez-Arrieta J, Rodriguez-Manas L, RodriguezArtalejo F. Effectiveness of acute geriatric units on functional decline, living at home, and case fatality among older patients admitted to hospital for acute medical disorders: meta-analysis. BMJ. 2009;338(jan22_2):b50-.

4. Fox MT, Sidani S, Persaud M, et al. Acute Care for Elders Components of Acute Geriatric Unit Care: Systematic Descriptive Review. Journal of the American Geriatrics Society. 2013;61(6):939-946.

5. Fox MT, Persaud M, Maimets I, et al. Effectiveness of Acute Geriatric Unit Care Using Acute Care for Elders Components: A Systematic Review and MetaAnalysis. Journal of the American Geriatrics Society. 2012;60(12):2237-2245.

6. Singler K, Holm EA, Jackson T, Robertson G, Muller-Eggenberger E, Roller RE. European postgraduate training in geriatric medicine: data of a systematic international survey. Aging Clin Exp Res. 2015;27(5):741-750.

7. EuSEM Task Force on Curriculum. European Curriculum for Emergency Medicine. Brussels: European Society for Emergency Medicine,

UEMS Multidisciplinary Joint Committee on Emergency Medicine;2009.

8. Union Européenne Des Médecins Spécialistes. http://www.uemsgeriatricmedicine.org/uems1/library1.asp. Accessed 19.12.14.

9. Callaway D, Wolfe R. Geriatric trauma. Emerg Med Clin North Am. 2007;25(3):837-860.

10. Samaras N, Chevalley T, Samaras D, Gold G. Older patients in the emergency department: a review. Annals of Emergency Medicine. 2010;56(3):261-269.

11. McCusker J, Verdon J, Vadeboncoeur A, et al. The Elder-Friendly Emergency Department Assessment Tool: Development of a Quality Assessment Tool for Emergency Department-Based Geriatric Care. Journal of the American Geriatrics Society. 2012;60(8):1534-1539.

12. Terrell KM, Hustey FM, Hwang U, Gerson LW, Wenger NS, Miller DK. Quality indicators for geriatric emergency care. Acad Emerg Med. 2009;16(5):441-449.

13. Geriatric Emergency Department Guidelines. Annals of Emergency Medicine. 2014;63(5):e7-e25.

14. Carpenter CR, Heard K, Wilber S, et al. Research priorities for high-quality geriatric emergency care: medication management, screening, and prevention and functional assessment. Acad Emerg Med. 2011;18(6):644-654.

15. Prendergast HM, Jurivich D, Edison M, Bunney EB, Williams J, Schlichting A. Preparing the front line for the increase in the aging population: geriatric curriculum development for an emergency medicine residency program. J Emerg Med. 2010;38(3):386-392.

16. Hogan TM, Hansoti B, Chan SB. Assessing knowledge base on geriatric competencies for emergency medicine residents. West J Emerg Med. 2014;15(4):409-413.

17. Hogan TM, Losman ED, Carpenter CR, et al. Development of geriatric competencies for emergency medicine residents using an expert consensus process. Acad Emerg Med. 2010;17(3):316-324.

18. Rowley E, Morriss R, Currie G, Schneider J. Research into practice: Collaboration for Leadership in Applied Health Research and Care (CLAHRC) for 


\section{The development of a European curriculum in Geriatric Emergency Medicine}

Nottinghamshire, Derbyshire, Lincolnshire (NDL). Implementation Science. $2012 ; 7(1): 40$.

19. Masud $T$, Blundell A, Gordon AL, et al. European undergraduate curriculum in geriatric medicine developed using an international modified Delphi technique. Age Ageing. 2014;43(5):695-702. 